\title{
A Little Less of the "Who Pays?"... ...A Little More of the "What For?"
}

\author{
J. Gordon Parr *
}

It was only after I had thrown away the second draft of this paper that I realized what was troubling me. I had only written about provincial difficulties of arranging equitable financial support for post-secondary institutions and students - a subject I shall come back to.

Such a talk might have been acceptable a couple of years ago. It might have been fair then to represent "provincial concerns in financing higher education" as the problems which form the story lines of the Bladen Commission's report, Hanly's "Who Pays?", and similar analyses. Of course, these problems are still with us. But an underlying question keeps interfering with attempts to get formulae, funds and fees in order. The questions is, roughly, "What are we paying for ?" or, more basically what are the purposes of post-secondary education? I am relieved to find that the CAUT makes a similar point. "The question, what is it that universities are supposed to be doing, or ought to be doing, for society, is apt to drop almost out of sight in discussions about the financing of post-secondary education in Canada."

When universities cost less, their purpose seemed to be satisfactorily defined. If people, or their governments, asked "What are we paying for ?" a number of answers were acceptable. "To educate leaders of men," "to safeguard the truth by uninhibited scholarship," "to free the mind" ; even that unspoken answer of the 1960's "to prepare people for jobs."

But universities have grown into public institutions, accommodating a wide spectrum of aptitudes, abilities, attitudes. And, paradoxically, as they have become more visible, their purpose eludes simple definitions.

During the period of university expansion, post-secondary resources in Canada became supplemented by the Colleges. Directed to vocational objectives, specifically serving a community, their programs extend from hard-line training, through general interest courses, to curricula whose academic content trespasses upon traditional univer-

* J. Gordon Parr, Deputy Minister, Colleges and Universities, Province of Ontario. 
sity ground. The question, "What are we paying for ?" directed to the Colleges, elicits easier answers. But the taxpayers' question, "Why are we paying for it ?" may, nevertheless, remain.

Most recently, we sense a trend to incorporate the less formalized resources of post-secondary learning into the educational complex : libraries, galleries, museums. Their open accessibility and, usually, their current poverty, add to the complexity of any funding program. Answers to the question "What are we paying for ?", are appreciated and understood by a wide audience.

What troubled me, as I threw into the wastebasket two substantial drafts of this paper and recycled their pulp in the mills of my mind, was that I had not come to grips with the right questions. I mean the questions whose answers permit springing funds from tax-generated revenues. Questions of purpose.

It is no longer a simple matter of finding a formula that distributes provincial grants among universities - or among universities and colleges ; or even among universities, colleges and those galleries, museums and libraries which are touched with provincial and federal gold.

It is no longer a matter of finding answers to questions about whether college courses should generate the same revenue as an apparently similar university course ; whether colleges should be funded for courses they give to people that want to enrich their leisure hours; whether theatre performances should be taxed, while courses in theatre are subsidized; how research should be funded. These are all part of the fabric of our confusion. But they do not penetrate to that key question of objectives.

The main issue lies in the extent to which post-secondary institutions wish to measure themselves against the market-place. To provide manpower is the maison d'être of the Colleges of Applied Arts and Technology in Ontario, and of similar sorts of colleges. But it is not the stated purpose of the university to provide manpower, even though universities have, through most of their history, trained people for specific purposes - for the church, medicine, law ; most notably, they have trained more teachers.

It seems to me that the universities cannot ignore the requirements of marketplace ; at the same time, they must do more than simply respond to manpower surveys. My greatest fear, however, is that if the universities do not more clearly recognize the sorts of work - and, no less important, the sorts of leisure activities - that motivate society, they will grow weak. And, growing weak, their institutional powers as seekers of truth, testers of opinion, proponents of reform, are jeopardized.

The paradox is that these characteristic and vital functions of the university are not self-supporting; they spring from a learning and scholarship that touches the real and dirty world.

One of the reasons for the decline in enrolment rate at the universities is a grow. ing feeling among potential students that the university does not prepare them for real- 
world pursuits. I believe that this concern is more critical in the U.S.A. than in Canada. The students who express this disillusionment do not expect the university to "train them for a job" (unless this is in law, medicine, divinity, teaching, and so on). But they do expect a closer relationship between their studies and their eventual lives.

One response to this criticism is that such a student should not seek university entrance- and there is probably some truth in this. But I rather think that this is a "cop-out." Such a response is usually framed within a supposition that universities are free-standing institutions that would go along pretty well without students. But as we support those university ideals of truth, scholarship, freedom in research, we have to realize that these all crumble unless they are continually treated with new generations of students. The work of the scholar, the importance of freely-expressed views, the frontiers of research, cannot reside in a static cadre of professors.

The student is central to the university. And the question in the minds of students, employers, the public, and government, is whether the student is being wellserved.

Even accepting the point of view that his university experience is solely for his intellectual development - and let this equip him for the market place (and it probably will) - is the student intellectually fulfilled ?

While our Colleges of Applied Arts and Technology do not have to wrestle with this question, they have their own problem, which is briefly, whether a trade or a skill, a technique, is better learned in school or on the job. The Colleges find themselves the victims of a pendulum swing of opinion. I suspect that if you took a survey of the countries of the western world, you would find pendulums swinging to this period in most positions of the arc.

Again, and with a much heavier emphasis on an eventual career, the postsecondary question is about the student. In what way is he best served ?

Cost and benefit analyses in the education arena do not mean very much : the benefit cannot be measured in the same currency as the cost. But governments would be irresponsible if they did not ask the obvious questions about costs. What are we paying for? What are the objectives of the institutions into which so much money is poured?

Since I have assumed the centrality of the student, it is reasonable to pursue this line in its implications on funding post-secondary education.

To a substantial extent, the student is already the vehicle on which government operating grants are made. The financial support given to universities and colleges depends upon enrolment. In Ontario, the provincial operating support grant to universities, represents more than $80 \%$ of university revenue. The remainder comes from fees a substantial proportion of which is generated from government grants and loans. The college situation is more complicated, because of an intricate involvement in selling services. But, putting aside training programs that are paid for by the sponsors, most 
of the financial support of colleges and universities comes from provincial grants made to the institutions, and a fair amount of the remainder comes from grants to students.

Now, although institutional grants are based upon a formula that is geared to student numbers, an alternative is obvious. That is, to put all the money in the hands of the students and let them go where they will. Increase fees to the level at which they meet the operating costs of the universities and colleges; and make available to students the amount of money that would have gone in formula grants to the institutions.

The next question is clear enough. Why single out the university and college student for this windfall? True, he is already the recipient of the windfall under current circumstances of post-secondary financing. But, when the money is put directly into his hands, with the instruction that he should go to study wherever he will, his privilege becomes much more apparent. And the person that wishes to study in different, non-institutionalized ways may reasonably ask why he, too, does not enjoy a grant for what be thinks is an educational purpose.

The Commission on Post-Secondary Education in Ontario tried to come to grips with this difficult problem. It recommended that funds should be provided for people who want to engage in post-secondary education, however, informal. It suggested that a greater proportion of operating revenue in college and university should derive from fees. And it recommended a student awards program that would make higher fees a practical proposition.

Let us consider the extreme position, where all of the universities' and colleges' revenue comes from fees. For the sake of simplicity, let us assume that the institutions are currently getting enough operating support to break even, and that student enrolment remains unchanged. Then, if fees were to cover costs, the institutions would collect the same revenue - but they would collect it from students. The provincial government would hand out the same amount of money - but the money would be delivered to students instead of directly to the universities.

We could break out the following comparative statements of revenue, by way of illustration :

Current system (operating grants)

Direct grant to institution :

Indirect grant via student fees

Student-paid fees :

$\begin{array}{rc} & \text { Total fee system } \\ 85 \% & \mathrm{Nil} \\ 5 \% & 90 \% \\ 10 \% & 10 \%\end{array}$

Any proportion of the $90 \%$ of indirect grant via student fees that could be transferred to a loan system would, of course, represent a saving in provincial expen. diture.

However tempting this may appear, we have to appreciate that while fees paid by students represent only about $10 \%$ of the revenue, they represent a substantial sum to each student. The student has to add it to his living expenses, book bills, forfeited 
earnings - baby-sitting costs, perhaps - at a time when he has little earned income. To this plea, of course, the taxpayer responds that the student is improving his subsequent earning ability. This may or may not be the case.

Before I try to summarize the advantages and disadvantages of providing operating funds through fees, let me make a couple of observations.

If provincial governments are to extend the availability of a wider spectrum of post-secondary resources to a larger community without expending more money, universities and colleges must absorb less funds. Hence, in order to derive operating revenue, they must be more substantially funded through fees, which, in turn, will have to derive from loan schemes rather than from government grants.

It is fairly generally accepted, though, that loan schemes turn away potential postsecondary candidates. For reasons which may be fascinating to analyse, but which do not help this paper one bit, many people are more prepared to go into debt for the hardware of television, or the software of vacation, than they are for a university or college course. (Our institutions should think about this!) Consequently, if accessibility to postsecondary education is to be improved, an extension of conventional loan schemes will probably be regressive : that is, the segment of population that is currently underrepresented in post-secondary institutions would be even less represented if loans to meet higher fees became the financing method.

There may be ways around this. But before I suggest one, we should not overlook the possibility that even the provision of non-repayable grants might not induce every academically able student to attend university or college. The reason may be that the thought has not been put in his (or her) way : and that is a pity. But, perhaps, the thought has been considered and rejected. After all, there are many views about what constitutes a full life, and there are many ways of achieving it.

One way of encouraging people to take a loan for educational purposes, is to describe the moneys as a grant which only becomes repayable when subsequent earnings reach a certain level. Of course this is the contingency-repayment scheme. But the manner of its description is important: it's not a loan which, under certain circumstances, is repayable.

Recalling the rough-and-ready comparison of revenue sources I suggested, it is obvious that any repayment over the figure of $10 \%$ of total institutional costs would represent a saving to government. The saving could be applied to provide other resources of higher education ; or to open up educational resources to people who, at present, are not beneficiaries.

If $I \mathrm{am}$ to be consistent in presenting a case for contingency repayments, the necessity for non-repayable grants disappears. Moneys provided to the student - to be passed on to the institution - are repaid on the basis of his subsequent earnings. His previous economic history should not affect this repayment. 
The usual rebuttal to this argument reminds us of the reluctance of lower income families to go into debt in order to buy an education. I have already suggested that the way in which the idea of contingency repayment is presented may have an influence. And I should add that I believe there are other factors at work than, simply, financial need, which dissuade the low-income student to enter university. A shortage of money is one symptom of a social condition. Nor would I be prepared to associate that social condition with underprivilege simply because it did not generate college and university students.

Let me add one other factor to this tangle. The theme of "Learning to be,' 'and "The Learning Society," (and this theme is by no means new) moves post-secondary education out of the 18 to 25 year-old age slot, to a resource for a wider spectrum of ages. While young, fulltime, students may continue to provide the greatest proportion of enrolment, they will not remain so predominant. And, when we look for the fairest ways of accommodating mature, part-time, students, funding via fees is attractive. The student can be financed on the same basis as the fulltime student, and is as financially attractive to the institution. Indeed, he may be in an advantageous position because, with a cooperative employer, he may have less hesitation in taking a loan. As his kind increases in number, and presents its fees to the university treasury - paying in full for its education - it stands a better chance of enjoying equal resources. Further, if universities and colleges find that they compete for the part-time student's fees against other, less formal, resources for which he might equally be funded, their treatment of the parttime student will improve.

Let me try to itemize some of the pro's and con's of such a system.

\section{POST-SECONDARY FUNDING VIA FEES, WITH SUBSTANTIAL STUDENT AID}

\section{Pros}

Promotes equal accessibility to all forms of post-secondary education

Effects a separation between government and the post-secondary institution or resource

With appropriate form of repayment, puts a greater part of the cost on the client

Any form of repayment lowers postsecondary costs to government

Gives the appearance of greater independ. ence to the student
Cons

The student - as the obvious recipient of public moneys - may become the target of public criticism more properly directed to the institutions

Organized militant student power might be a greater threat to institutional integrity than are governments

Difficult to manage

A reluctance to accept moneys with any qualification of repayment may be a deterrent to particular social sectors Unanswered questions about federal involvement. 
The two extremes I have suggested so far are:

1. Substantially funding colleges and universities by a formula depending upon enrolment. Only a small proportion of revenue is generated by student fees actually found by the student. This is the current scheme in Ontario and in other provinces.

2. Funding colleges and universities entirely through student fees; providing students with grants to enable them to pay the necessarily higher fees; anticipating some return by contingency repayments of these grants.

Both systems have the common feature of funding the universities to an extent that depends upon enrolment. Weighting factors in the formulae may steer enrolment into particular subjects or levels. And both systems - or any intermediate positions permit an institution to expand its resources as its enrolment increases. Neither system, however, accommodates the institution whose enrolment is declining.

Financing which is student-based is hazardous when enrolment declines. It automatically leads to a public attitude which seems to say that for every fifteen-or-so students less, we should expect that one faculty member will be let go. After all, the institution enjoyed a corresponding increase of staff when enrolments climbed.

For all that one may insist that universities and colleges should be student-oriented (a point of view which I share), there has to be some safeguard against allowing the institution to fall apart through a temporary enrolment decline.

Again - and for the sake of example - let me suggest an extreme point of view : to fund universities and colleges to an amount that is totally independent of student enrolment, and allow the institution to accommodate whatever numbers of students it believes it can. Blatant abuses of such a system can be guarded against. But the principle is contrary to any ideal that opens up post-secondary education to all who are qualified. Fixed operating grants to universities can only mean fixed quotas of students. And, however cynical one may be about the meaning of secondary school diplomas and postsecondary admission standards, these do seem to offer fairer access than arbitrary quotas.

Perhaps one has to strike an intermediate position : a proportion of funding that is not based upon student numbers - perhaps it should depend upon the scholarship and research of the faculty; a proportion that is paid directly to the university dependant upon student enrolment; and a substantial fee paid by the student. Such a position appears to align me with some of the recommendations of the Commission on PostSecondary Education. The principal exception is that I differ in the apportioning of grants and loans.

I will itemize three other matters. First, the financing process that allows a student to enjoy the currently accepted modes of post-secondary education (these are generally institutionalized), should not be denied the person that conscientiously wishes to follow less traditional patterns. 
Second, any financing process should encourage the part-time student and the mature student.

Third, we have to ask the question - and I cannot attempt to answer it whether student support, distinct from payment for tuition, should be based upon an educational resource or upon a welfare resource.

But as I try to identify these questions I continually return to the basic issue of purpose. What are we paying for?

Government moved into the post-secondary education arena to provide massive funding to sustain the growth of universities and colleges. Government itself encouraged that growth. The encouragement was honest enough: better education for a bigger proportion of the population appeared to be a tonic for social and economic well-being.

During the period of most rapid growth, in the 1960's, government departments of higher education were, generally, administrators of transfer payments to colleges and universities. In many jurisdictions government was advised by committees of various sorts, with various powers. In most cases, the committees that advised on universities were careful to avoid questions that trespassed upon university autonomy; hence their advice was almost entirely about the level of funding and its distribution. Colleges - at any rate, those in Ontario - were more directly influenced in their practices by government and advisory boards.

But whatever the intermediate structure between institution and government, the dilemma remains : the Minister is fully accountable to the public through Parliament; but the institution is only partially accountable to the Minister. By partially, I mean, for example, that it has to present audited bookkeeping, but it does not have to justify, except in the most general way, its academic actions.

The dilemma grows as the territory of post-secondary education becomes a public property. One of the inevitable results of more education is that education is a more common topic of public scrutiny.

The tonic value of education is not in doubt. Indeed, there is a growing acceptance that education is more a staple food than a tonic. But while, in years past, the educators themselves were allowed to prescribe the tonic, the public of the 1970's - and its governments - are necessarily involved in the distribution and nature of what have become food staples. Therefore, while government responsibility used to reside in the distribution of grants, it has now grown to incorporate fundamental questions of purpose. A survey of government and government-sponsored reports over the past couple of decades substantiates this point.

Hence government concerns - these are public concerns - about financing higher education are more penetrating than they were in the 1960's. Established institutions of post-secondary education must develop an integrity in a growing complex of 
post-secondary pursuits. To do this, they should allow that they are not all things to all people.

The mandate of the colleges is more clearly defined than that of the universities. But the relationship of on-site training to in-school training, and the associated movement of fiscal responsibility between levels of governments and industry and business, call for a clear expression of purpose.

In the universities, to whatever extent the market-place is heeded, there is the difficult question of whether the intellectual aspirations of students are fulfilled. To be able to reason, to enjoy knowledge, to try to understand, should be justified in the context of both work and leisure. If they are not to be unwittingly steered by accidents or intentions of government-derived financing formulae, the purpose of the university in a new learning environment, and after a decade of rapid growth - has to be declared. Not only declared, but demonstrated. 